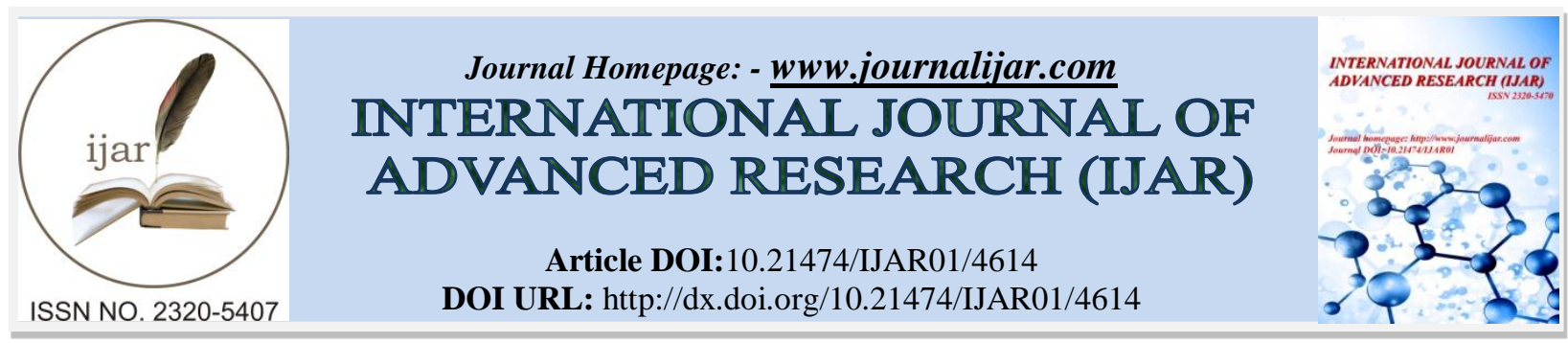

RESEARCH ARTICLE

\title{
CLINICAL OUTCOMES AND QUALITY OF LIFE IN PATIENTS WITH ACS TREATED WITH CONCOMITANT USE OF TICAGRELOR AND CLOPIDOGREL.
}

1. Chapidze Emergency Cardiology Center.

\section{Kopaleishvil ${ }^{1}$ and I. Jashi ${ }^{2}$.}

2. Institute of Clinical Cardiology.

\section{Manuscript Info}

(.........................

Manuscript History

Received: 25 April 2017

Final Accepted: 27 May 2017

Published: June 2017

Key words:-

acute coronary syndrome, clopidogrel, quality of life, SF-36, ticagrelor

\section{Abstract}

Objectives: The purpose of our study was to compare the effects of ticagrelor versus clopidogrel on the quality of life (QOL) in patients with acute coronary syndrome (ACS) at admission and at 12 months after antiaggregant treatment. Methods: Data was collected from 104 patients hospitalized for ACS. Patients were assigned to ticagrelor (group I) or to clopidogrel (group II) therapy. In order to measure QOL a Medical Outcomes Study Short-Form (SF)-36 was used. It contained 36 questions to measure 8 domains: physical status, social functioning, role limitations due to physical and emotional problems, mental health, energy/vitality, bodily pain, general health perception and change in health over the past year. The final score was transformed to a 100-point scale, where 100 is the best possible health. Results: The number of points for each question of the physical status and mental state indicators before antiaggregant therapy ranged from 0 to 100 . In ticagrelor group the total number of points averaged 25.91 \pm 14.7 . In the post treatment phase positive dynamics has been observed. It significantly $(\mathrm{p}<0.004)$ increased and reached 77.24 \pm 8.8 . In clopidogrel group the total number of points averaged $25.93 \pm 14.2$, and also increased and reached $71.38 \pm 8.0$ after the treatment $(\mathrm{P}<0.004)$. In the pain domain better results were achieved in the ticagrelor group. Statistically significant difference was recorded $(\mathrm{P}<0.001)$. Analysis of the mental state indicators in post-treatment phase revealed statistically significant increase in ticagrelor and clopidogrel groups. Social activity was higher in ticagrelor group. Statistically significant difference was recorded $(\mathrm{P}<0.001)$. The change in health status of the patients of the $1^{\text {st }}$ and $2^{\text {nd }}$ groups compared to the previous year improved and increased by $31 \%$ and 28\% respectively. Conclusion: ticagrelor and clopidogrel treatment resulted in improvement of QOL in patients with ACS. No treatment difference in QOL between patients treated with ticagrelor and patients treated with clopidogrel was found, except pain and social activity. According to these indicators reliably better result was achieved in patients treated with ticagrelol. Prior cardiovascular events and baseline psychosocial characteristics, including depressive symptoms, were predictors of QOL for patients after ACS. 
Copy Right, IJAR, 2017,. All rights reserved.

\section{Introduction:-}

It has been more than 15 years since revolutionary strategies of acute coronary syndromes (ACS) management have been introduced. The innovations have occurred in the area of interventional cardiology (bare metal evolving to drug-eluting stents) and in pharmacotherapy, particularly anti-platelet therapy.

Platelets role in the development of the thrombus is significant (1). In addition to the physiological function of platelets in formation of the thrombotic occlusion in ACS, it has been suggested that there exists certain relationship between platelet activity and clinical outcomes. Besides, platelet aggregation is a major contributor to microcirculatory dysfunction in ACS (2).

Since increased platelet activity is an important driver of outcomes in both NSTE-ACS and STEMI antiplatelettherapy becomes a cornerstone of medical management in patients with ACS.

Comparing ACS therapies and assessment of the impact of the disease on the patients requires accurate assessmentof quality of life (QOL) and symptom scales (3-5).

Health-related QOL measures make it possible to evaluate health across multiple domains: physical, functional, psychological and social. QOL measures are useful when interventions or treatments are indicated for several reasons, such as pain relief and improvement of physical functioning. QOL measures may be used to predict other clinical outcomes, particularly mortality, and to estimate the effectiveness or cost-effectiveness of therapies from a societal- or population-based perspective. These instruments also reflect a patient-centered focus rather than more traditional end points, such as hospitalization or death. Medical therapy aims to improve QOL, as well as to reduce symptoms and to prolong lifespan. Therefore, the measurement of QOL as a primary outcome is justified.

The purpose of our study was to compare the effects of ticagrelor versus clopidogrel on QOL in patients with ACS.

\section{Methods:-}

Patients hospitalized for potential ST-segment elevation or non-ST-segment elevation ACS, with onset during the previous 24 hours were examined. For non-ST-segment elevation ACS, at least 2 of the following 3 criteria were required: ST-segment depression or transient elevation $\geq 1 \mathrm{~min}$ in 2 or more contiguous leads, positive biomarker indication myocardial necrosis, or 1 additional risk indicator: age $>60$ years, history of myocardial infarction or coronary artery bypass graft (CABG), carotid artery disease, history of ischemic stroke, transient ischemic attack, carotid stenosis or cerebral revascularization, diabetes mellitus, peripheral artery disease, or chronic kidney disease (CKD) (creatinine clearance $[\mathrm{CrCl}]<60 \mathrm{ml} / \mathrm{min}$ estimated by Cockroft-Gault equation). For ST-segment elevation ACS, inclusion required a planned primary percutaneous coronary intervention. The most important exclusion criteria were fibrinolytic therapy within 24 hours, need for oral anticoagulation therapy, need for dialysis, and clinically important anemia or thrombocytopenia.

Patients were randomly assigned to ticagrelor (group I) or clopidogrel (group II) therapy before any percutaneous coronary intervention procedure was performed. Ticagrelor was given in a loading dose of $180 \mathrm{mg}$ followed by 90 $\mathrm{mg}$ twice daily. Patients involved in clopidogrel group who had not taken clopidogrel for at least 5 days before, were given $300 \mathrm{mg}$ loading dose of clopidogrel followed by $75 \mathrm{mg}$ daily. Others continued a maintenance dose of $75 \mathrm{mg}$ daily as clopidogrel study drug. All patients received acetylsalicylic acid unless intolerant. A daily dose of 75 to 100 mg was recommended. The median duration of study treatment was 11.3 months.

In order to measure QOL a Medical Outcomes Study Short-Form (SF)-36 was used. The SF-36 contained 36 questions to measure 8 domains, including physical functioning (ten questions), social functioning (two questions), role limitations due to physical problems (four questions), role limitations due to emotional problems (three questions), mental health (five questions), energy/vitality (four questions), bodily pain (two questions), general health perception (five) and change in health over the past year (one question) (6). As with the SWED-QUAL, the final score is transformed to a 100-point scale, where 100 is the best possible health. 
The measurement of QOL was made at admission and twelve months after the treatment with study drug. It was feasible for patients with STEMI to fill this entire questionnaire before primary PCI. This delayed the PCI procedure only of abou $15 \mathrm{~min}$.

Statistical analysis. Comparative statistics was conducted using Student's t test as well as Paired samples test for assessment before and after the treatment. Student's t-test for Independent samples was used for ticagrelor and clopidogrel groups; the equality of variances was determined using Levene's test. SPSS 22 was used for statistical analysis.

\section{Results:-}

All baseline characteristics and non-study medications are shown at Table 1 and Table 2, respectively.

Table 1:- Baseline characteristics of the patients

\begin{tabular}{|c|c|c|}
\hline Characteristics & Ticagrelor, Group I(N-51) & Clopidogrel, Group II (N-53) \\
\hline Median age - yr & 58.0 & 59.0 \\
\hline Age $\geq 75$ yr-no./total no (\%) & $5 / 51(9.8)$ & $5 / 53(9.4)$ \\
\hline Female sex- no./total no. (\%) & $10 / 51(19.6)$ & $11 / 53(20.7)$ \\
\hline Median body weight- kg (range) & 81.0 & 79.2 \\
\hline \multicolumn{3}{|l|}{ Cardiovascular risk factor- no./total no. (\%) } \\
\hline Habitual smoker & $22 / 51(43.1)$ & $23 / 53(43.3)$ \\
\hline Hypertension & $35 / 51(68.6)$ & $36 / 53(67.9)$ \\
\hline Dyslipidemia & $18 / 51(35.2)$ & $19 / 53(35.8)$ \\
\hline Diabetes mellitus & $10 / 51(19.6)$ & $12 / 53(22.6)$ \\
\hline \multicolumn{3}{|l|}{ Other medical history- no./total no. $(\%)$} \\
\hline MI & $12 / 51(23.5)$ & $13 / 53(24.5)$ \\
\hline Percutaneous coronary intervention & $7 / 51(13.7)$ & 9/53 (16.9) \\
\hline Coronary-artery bypass grafting & $2 / 51(3.9)$ & $2 / 53(3.7)$ \\
\hline Congestive heart failure & $4 / 51(7.8)$ & $4 / 53(7.5)$ \\
\hline Nonhemorrhagic stroke & $2 / 51(3.9)$ & $2 / 53(3.7)$ \\
\hline Peripheral arterial disease & $2 / 51(3.9)$ & $3 / 53(5.6)$ \\
\hline Chronic renal disease & $1 / 51(1.9)$ & $1 / 53(1.8)$ \\
\hline History of dyspnea & $3 / 50(5.8)$ & $2 / 53(3.7)$ \\
\hline Chronic obstructive pulmonary disease & $2 / 51(3.9)$ & $1 / 53(1.8)$ \\
\hline Gout & $1 / 51(1.9)$ & $1 / 53(1.8)$ \\
\hline \multicolumn{3}{|l|}{ ECG findings at study entry- no./total no. (\%) } \\
\hline Persistent ST-segment elevation & $14 / 51(27.4)$ & $13 / 53(24.5)$ \\
\hline ST-segment depression & $14 / 51(27.4)$ & $15 / 53(28.3)$ \\
\hline T-wave inversion & $19 / 51(37.2)$ & $18 / 53(33.9)$ \\
\hline $\begin{array}{l}\text { Positive troponin I test at study entry- no./total } \\
\text { no. }(\%)\end{array}$ & $35 / 51(68.6)$ & $35 / 53(66.0)$ \\
\hline \multicolumn{3}{|l|}{ Final diagnosis of ACS- no./total no. (\%) } \\
\hline ST-elevation MI & $14 / 51(27.4)$ & $13 / 53(24.5)$ \\
\hline Non-ST elevation MI & $21 / 51(41.1)$ & $22 / 53(41.5)$ \\
\hline Unstable angina & $15 / 51(29.4)$ & $17 / 53(32.0)$ \\
\hline Other diagnosis or missing data & $1 / 51(1.9)$ & $1 / 53(1.8)$ \\
\hline \multicolumn{3}{|l|}{$\begin{array}{c}\text { Risk factors for } \\
\text { ST-elevation MI - no./total no. }(\%)\end{array}$} \\
\hline Killip class $>2$ & $3 / 14(21.0)$ & $3 / 13(23.1)$ \\
\hline TIMI risk score $\geq 3$ & $5 / 14(35.7)$ & $4 / 13(30.7)$ \\
\hline \multicolumn{3}{|l|}{$\begin{array}{c}\text { Risk factors for non-ST elevation MI- no./total } \\
\text { no. }(\%)\end{array}$} \\
\hline Positive troponin I test & $20 / 21(95.8)$ & $21 / 22(95.9)$ \\
\hline ST-segment depression $>0.1 \mathrm{mV}$ & $17 / 21(80.9)$ & $18 / 22(81.8)$ \\
\hline TIMI risk score $\geq 5$ & $1 / 21(4.7)$ & $2 / 22(9.2)$ \\
\hline
\end{tabular}


Table 2:- Treatments according to test groups

\begin{tabular}{|c|c|c|}
\hline Characteristics & Ticagrelor, Group I (N=51) & Clopidogrel, Group II (N=53) \\
\hline $\begin{array}{c}\text { Other medication administered in hospital or at } \\
\text { discharge - no (\%) }\end{array}$ & & \\
\hline Organic nitrate & $38(74.5)$ & $40(75.4)$ \\
\hline Beta-blocker & $44(86.2)$ & $45(84.9)$ \\
\hline Ace inhibitor & $42(82.3)$ & $7(13.2)$ \\
\hline Angiotenzin-II-receptor blocker & $8(15.6)$ & $45(84.9)$ \\
\hline Cholesterol-lowering drug (statin) & $47(89.7)$ & $14(26.4)$ \\
\hline Calcium-channel inhibitor & $15(29.4)$ & $22(41.5)$ \\
\hline Proton-pump inhibitor & $21(45.4)$ & \\
\hline
\end{tabular}

ACE - angiotensin-converting enzyme; CABG - coronary-artery bypass grafting.

Study drug was given to the patients of both groups at a median of 10.7 hours (interquartile range, 4.3 to 14.1 ) after the onset of the chest pain. The median duration of exposure to the study drug was 331 days (interquartile range, 298 to 365$)$.

Dyspnea was more common in the ticagrelor group than in the clopidogrel group (in $7.8 \%$ of patients vs. $3.7 \%$ ).

Discontinuation of the study drug due to adverse events occurred more frequently with ticagrelor than with clopidogrel (in $5.8 \%$ of patients vs. $1.8 \%$, p<0.05).

Overall 108 patients were involved in the study and 104 of them were evaluated. With this purpose our patients were asked to fill special questionnaires before and after the treatment.

The number of points of the quality of life according to the physical component is given below in table 3 .

Table 3:- The number of points of physical components in pre- and post treatment phases

\begin{tabular}{|c|c|c|c|c|c|c|c|c|}
\hline & \multicolumn{4}{|c|}{ I group } & \multicolumn{4}{|c|}{ II group } \\
\hline & $\begin{array}{c}\text { Before } \\
\text { treatment }\end{array}$ & $\begin{array}{c}\text { after } \\
\text { treatment }\end{array}$ & $\mathrm{t}$ & $\mathrm{p}$ & $\begin{array}{c}\text { Before } \\
\text { treatment }\end{array}$ & $\begin{array}{c}\text { after } \\
\text { treatment }\end{array}$ & $\mathrm{t}$ & $\mathrm{p}$ \\
\hline Physical status & $13.24 \pm 2.970$ & $77.94 \pm 14.635$ & -29.38 & 0.001 & $13.30 \pm 2.764$ & $\begin{array}{c}75.09 \pm 13.78 \\
0\end{array}$ & -32.43 & 0.001 \\
\hline $\begin{array}{l}\text { The role of the } \\
\text { physical status in } \\
\text { different activities }\end{array}$ & $47.06 \pm \frac{ \pm}{4} 24.31$ & $84.80 \pm 26.962$ & -9.20 & 0.01 & $46.23 \pm \frac{24.21}{7}$ & $80.66_{\frac{2}{9}} 27.57$ & -7.60 & 0.01 \\
\hline Pain & $23.04 \pm 6.171$ & $81.42 \pm 19.864$ & -21.24 & 0.01 & $23.40 \pm 5.678$ & $66.37 \pm \frac{18.45}{3}$ & -17.29 & 0.001 \\
\hline Generalhealth & $20.29 \pm 4.941$ & $64.80 \pm 18.761$ & -17.44 & 0.01 & $20.78 \pm 4.799$ & $63.40 \pm 18.26$ & -17.18 & 0.01 \\
\hline
\end{tabular}

Indicators in the table are given as Mean \pm St Dev, $P$ - statistically significant in comparison with the initial indicators.

The number of points for each question of the physical status indicators before antiaggreganttherapy ranged from 0 to 100 . In ticagrelor group the total number of points averaged $25.91 \pm 14.7$. In the post treatment phase positive dynamics has been observed. It increased and reached 77.24 $\pm 8.8(\mathrm{P}<0.004)$. In clopidogrel group the total number of points averaged $25.93 \pm 14.2$. In the post treatment phase positive dynamics has been observed. It increased and reached 71.38 $\pm 8.0(\mathrm{P}<0.004)$. In the pain domain better results were achieved in the ticagrelor group. Statistically significant difference was recorded $(\mathrm{P}<0.001)$. 
The number of points of the quality of life according to the mental components is given below in table 4 .

Table 4:- The number of points of mental components in pre- and post treatment phases

\begin{tabular}{|c|c|c|c|c|c|c|c|c|}
\hline & \multicolumn{4}{|l|}{ I group } & \multicolumn{4}{|l|}{ II group } \\
\hline & $\begin{array}{l}\text { Before } \\
\text { treatment }\end{array}$ & $\begin{array}{l}\text { after } \\
\text { treatment }\end{array}$ & $\mathrm{t}$ & $\mathrm{p}$ & $\begin{array}{l}\text { Before } \\
\text { treatment }\end{array}$ & $\begin{array}{l}\text { after } \\
\text { treatment }\end{array}$ & $\mathrm{t}$ & $\mathrm{p}$ \\
\hline Energy & $18.33 \pm 2.380$ & $\begin{array}{r}69.61 \pm 16.7 \\
88 \\
\end{array}$ & $-\overline{21.08}$ & 0.01 & $18.96 \pm 2.047$ & $68.21 \pm 16.788$ & -21.09 & 0.01 \\
\hline Socialactivity & $25.25 \pm 6.369$ & $\begin{array}{r}79.66 \pm 20.1 \\
50 \\
\end{array}$ & $\begin{array}{l}- \\
18.60 \\
\end{array}$ & 0.01 & $25.24 \pm 4.580$ & $59.20 \pm 16.103$ & -14.65 & 0.001 \\
\hline $\begin{array}{l}\text { The roleof the } \\
\text { emotional state in } \\
\text { different } \\
\text { activities }\end{array}$ & $\begin{array}{l}58.84 \pm 14.30 \\
9\end{array}$ & $\begin{array}{r}94.12 \pm 12.8 \\
21\end{array}$ & $\begin{array}{l}- \\
11.71\end{array}$ & 0.001 & $64.18 \pm 8.907$ & $91.20 \pm 14.822$ & -12.23 & 0.01 \\
\hline Emotionalstate & $20.86 \pm 3.027$ & $\begin{array}{r}72.86 \pm 15.4 \\
16 \\
\end{array}$ & $\overline{24.23}$ & 0.001 & $20.38+2.388$ & $73.02 \pm 14.825$ & -25.55 & 0.001 \\
\hline
\end{tabular}

Indicators in the table are given as Mean \pm St Dev, $P$ - statistically significant in comparison with the initial indicators.

The number of points for each question of the mental state indicators before antiaggregant therapy ranged from 0 to 100. In ticagrelor group the total number of points averaged $30.82 \pm 18.89$. In the post treatment phase positive dynamics of a given parameter has been observed. It increased and reached $79.06 \pm 10.87(\mathrm{P}<0.002)$. In clopidogrel group the total number of points averaged 32.19 \pm 21.49 . In the post treatment phase positive dynamics of a given parameter has been observed. It increased and reached $72.91 \pm 13.47(\mathrm{P}<0.007)$. Social activity was higher in ticagrelor group. Statistically significant difference was recorded $(\mathrm{P}<0.001)$ (Table 5).

Table 5:- Compared of physical and mental components in both groups after treatment

\begin{tabular}{|c|c|c|c|c|}
\hline & $\mathrm{n}=51$ & $\mathrm{n}=53$ & \multirow[t]{2}{*}{$\mathrm{t}$} & \multirow[t]{2}{*}{$\mathrm{p}$} \\
\hline & I & II & & \\
\hline Physical status & $77.94 \pm 14.635$ & $75.09 \pm 13.780$ & 1.02 & 0.3099 \\
\hline $\begin{array}{l}\text { The role of the physicalstatus in } \\
\text { different activities }\end{array}$ & $84.80 \pm 26.962$ & $80.66 \pm 27.579$ & 0.77 & 0.4403 \\
\hline Pain & $81.42+19.864$ & $66.37 \pm 18.453$ & 4.00 & 0.0001 \\
\hline General health & $64.80 \pm 18.761$ & $63.40 \pm 18.260$ & 0.39 & 0.6991 \\
\hline Energy & $69.61 \pm 16.788$ & $68.21 \pm 16.788$ & 0.43 & 0.6716 \\
\hline Socialactivity & $79.66+20.150$ & $59.20 \pm 16.103$ & 5.71 & 0.001 \\
\hline $\begin{array}{l}\text { The roleof the emotional state in } \\
\text { different activites }\end{array}$ & $94.12 \pm 12.821$ & $91.20 \pm 14.822$ & 1.08 & 0.2847 \\
\hline Emotionalstate & $72.86 \pm 15.416$ & $73.02+14.825$ & -0.05 & 0.9581 \\
\hline
\end{tabular}

Indicators in the table are given as Mean \pm St Dev, $P$ - statistically significant between the groups after the treatment.

The change in health state of the patients of the $1^{\text {st }}$ and $2^{\text {nd }}$ groups compared with the previous year increased by $31 \%$ and $28 \%$ respectively.

Therefore, after antiaggregant treatment the QOL in studied population improved according to the both components. Statistically significant increase of the average number of points has been revealed. Though, it must be mentioned that the number of points of some of the patients hasn't changed significantly in the post-treatment phase. It means that the quality of their lives hasn't improved. Particularly, according to the physical component, the QOL improved in 75 cases $(72 \%)$ out of 104 patients involved in the study. In the rest 29 cases $(28 \%)$ it remained unchanged. The same data was obtained in mental component. Increase in the number of points (i.e. improvement of the QOL) was identified in the majority of patients $-70(67 \%)$, while in the rest of the cases - $34(32 \%)$ there was no statistically significant change of the number of points. This indicates that according to the mental component in the posttreatment phase the QOL of these patients hasn't improved. 
Improvement by both physical and mental components was not revealed in those patients with low baseline QOL scores.

Statistical analysis of the indicators revealed some factors that led to nonsignificant improvement of the physical and mental components of the QOL in those patients. With regard to the physical component there were identified such factors as feminine gender, elderly age, multiplicity of traditional for coronary atherosclerosis risk factors: diabetes mellitus, arterial hypertension, excessive body weight, obesity, metabolic syndrome, history of myocardial infarction, low left ventricular ejection fraction, CHF (III-IV NYHA class) and accompanying diseases such as hypothyroidism, COPD and also coronary relapses.

The same data was obtained with regard to the mental component. Though along with the above identified factors some other additional factors have been revealed, which have negative influence on the quality of life. These factors are unemployment, giving up smoking, lack of exercises and hereditary load.

\section{Discussion:-}

It has been generally accepted that the final goal of any treatment is not only increasing lifespanof a patient, but also improving of the QOL. Such approach led to the need to study the dynamics of the QOL among our patients before and after antiaggregant therapy.

Several studies using the EQ-5D questionnaire to assess QOL among patients with coronary heart disease have been conducted (7-11), but only a few of them have used it in the subset of patients with ACS $(12,13)$. The MERLINTIMI 36 Randomized trial of Ranolazine versus placebo had been carried out in 6560 patients with non-STelevation ACS reported an EQ-5D questionnaire single index value of approximately 0.71 at baseline and 0.84 at 12 months. PLATO study enrolled only patients with symptom onset during the previous 24 hours (14). In acute settings it was difficult to obtain a true baseline when measuring the health-related QOL. Therefore, their first EQ$5 \mathrm{D}$ questionnaire measure, the assessment made at discharge from the index hospitalization, cannot be considered as a true baseline because it is reported after treatment initiation of the study drug. However, the values of EQ-5D questionnaire at 12 months corresponded to those reported in the MERLIN_TIMI 36 study.

Comparison of the QOL of patients after an episode of ACS with a control population showed that it doesn't significantly differ from the latter and is generally high $(15,16)$. Thereby, long-term preventive treatment with ticagrelor as compared to clopidogrel (unlike some other secondary preventive treatments such as antihypertensives) led to the benefits in survival and reduction of cardiovascular events without any impediment to the QOL in these patients (17).

It is generally accepted that the goal of health-related QOL studies is identifying of the change in QOL. However, baseline indicators of QOL prior to treatment were not collected in the PLATO trial. Consequently, this study provided assessment of absolute rather than relative difference in QOL at 12 months. Health-related QOL was evaluated by means of only the generic EQ-5D questionnaire instrument. The use of this tool is advantageous as it is easy to complete for the patients, it can be incorporated into case report forms, and is validated in many languages, but it may be less sensitive than a disease-specific QOL instrument $(17,18)$. In addition, the EQ-5D questionnaire single index reflects health status derived by using an algorithm based on utility scores from a reference population. Accordingly it might not provide a truly personal evaluation of health status.

In order to obtain the patients' subjective assessment of their QOL, in our study we used the physical and mental component summary scales of the Georgian version of the Short Form Health Survey (SF-36) (19). Our preference in choosing this general QOL instrument rather than more specific tools was conditioned by the fact that it provides an assessment of subjects' own perception of their QOL as a function of their general state of health.

Subsequently, the scores obtained on the physical and mental summary scales of SF-36 were used to assess physical and mental QOL respectively (20).

The results of the study showed that in $11.3 \pm 1.1$ months' period after antiaggregant treatment reliable improvement of patients life was observed for the following 8 indicators: physical state, the role of physical state in different activities, pain, general physical state, emotional state, the role of emotional state in different activities, social 
activity and energy. Positive results were obtained in the $9^{\text {th }}$ additional indicator as well. Evaluation of this indicator was carried out in the post treatment phase.

The results of antiaggregant treatment showed that the QOL of the patients involved in the study improved in both components. Statistically significant increase compared to the initial data was identified. But it must be also mentioned that according to our study the QOL of some patients didn't improve. The analysis of the questionnaires didn't show significant change in the number of points. It means that the quality of life in these cases didn't improve either by physical or by mental components.

In addition, it was revealed that QOL scores have a predictive value to the usual prognostic measures. The fact that certain patient's characteristics are predictive for QOL and prognosis obviously has clinical implications and highlights the need for assessment and monitoring of QOL following ACS.

\section{Conclusion:-}

QOL in patients with ACS improved in the result of treatment with ticagrelor and clopidogrel.

No treatment difference in QOL between patients treated with ticagrelor and patients treated with clopidogrel were found, except of pain and social activity. According to these indicators reliably better result was achieved in patients treated with ticagrelor.

Prior cardiovascular events and baseline psychosocial characteristics, including depressive symptoms, are predictors of QOL for patients after ACS.

These results highlight the importance of routine clinical assessment of QOL and depressive symptoms in patients admitted for ACS, in order to select the most appropriate therapeutic options that may lead to the improvement in QOL, particularly in patients with lower baseline QOL scores.

\section{Conflict of interest: not declared}

\section{References:-}

1. Theroux P, Fuster V. Acute coronary syndromes. Unstable angina and non-Q wave myocardial infarction. Circulation 1998; 97:1195-1206

2. Steinhubl SR, Talley JD, Braden GA, Tcheng JE, Casterella PJ, Moliterno DJ, Navetta FI, Berger PB, Popma JJ, Dangas G, Gallo R, Sane DC, Saucedo JF, Jia G, Lincoff AM, Theroux P, Holmes DR, Teirstein PS, Kereiakes DJ. Point-of-care measured platelet inhibition correlates with a reduced risk of an adverse cardiac event after percutaneous coronary intervention results of the GOLD (AU-Assessing Ultegra) multicenter study. Circulation 2001;103:2572-2578

3. Brink E, Grankvist G, Karlson BW, et al. Health-related quality of life in women and men one year after acute myocardial infarction. Qual Life Res 2005;14:749-757

4. Hawkes AL, Patrao TA, Ware R, et al. Predictors of physical and mental health-related quality of life outcomes among myocardial infarction patients. BMC Cardiovasc Dis 2013;13:69

5. Pavlides G, Drossinos V, Dafni C, et al. Current management and quality of life of patients with acute coronary syndrome undergoing percutaneous coronary intervention in Greece: 12-month results from antiplatelet therapy observational study II (APTOR II). Hellenic J Cardiol 2013;54:255-263

6. Stewart AL, Hays RD, Ware JE. The MOS Short-form General Health Survey: reliability and validity in patient population. Med Care 1988;26:724-735

7. Schweikert B, Hahmann H, Leidl R. Validation of the EuroQoLquestionnaire in cardiac rehabilitation. Heart 2006;92:62-67

8. Hage C, Mattsson E, Stahle A. Long-term effects of exercise training on physical activity level and quality of life in elderly coronary patients - a three- to six-year follow-up. Physiother Res Int 2003;8:13-22

9. Kruse M, Hochstrasser S, Zwisler AD, et al. Comprehensive cardiac rehabilitation: a cost assessment based on a randomized clinical trial. Int J Technol Assess Health Care 2006;22:478-483

10. Lacey EA, Musgrave RJ, Freeman JV, et al. Psychological morbidity aftermyocardial infarction in an area of deprivation in the UK: evaluation of a self-help package. Eur J Cardiovasc Nurs 2004;3:219-224 
11. Kim J, Henderson RA, Pocock SJ, et al. Health-related quality of life after interventional or conservative strategy in patients with unstable angina or non-ST-segment elevation myocardial infarction: one-year results of the third Randomized Intervention Trial of unstable Angina (RITA-3). J Am Coll Cardiol 2005;45:221-228

12. Arnold SV, Morrow DA, Wang K, et al. Effects of ranolazine on disease-specific health status and quality of life among patients with acute coronary syndromes: results from MERLIN-TIMI 36 randomized trial. Circ Cariovasc Qual Outcomes 2008;1:107-115

13. Azmi S, Goh A, Fong A, Anchah L. Quality of life among patients with acute coronary syndrome in Malaysia. Value in health regional issues 6C (2015), 80-83

14. Levin L-A, Wallentin L, Bernfort L, et al. Health-related quality of life of ticagrelor versus clopidogrel in patients with acute coronary syndromes - results from the PLATO trial. Value in Health 2013; 16:574-80

15. Janzon M, Levin LA, Swahn E. Invasive treatment in unstable coronary artery disease promotes health-related quality of life: results from the FRISC II trial. Am Heart J 2004;148:114-21

16. Swedeheart Arsrapport (Annual report). Uppsala, Sweden: UCR, 2010

17. Brazier J, Fitzpatrick R. Measures of health -related quality of life in an imperfect world: a comment on Dowie. Health Econ 2002;11(1):17-9: discussion 21-22

18. Guyatt G. Commentary on Jack Dowie, "Decision validity should determine whether a generic or conditionspecific HRQOL measure is used in health care decisions". Health Econ 2002;11(1):9-12: discussion 21-22

19. Ware J, Kosinski M, Keler S. SF-36 physical and mental health summary scales: a user's manual. $5^{\text {th }}$ ed. Boston: Health Assessment Lab; 1994

20. 20.Ware JE. SF-36 physical and mental health summary scales. Ann Rev Public Health 1995;16:327-354 